\title{
Interphase cytogenetics using biotin and digoxigenin labelled probes I: relative sensitivity of both reporter molecules for detection of HPV16 in CaSki cells
}

\author{
C S HERRINGTON, J BURNS, A K GRAHAM, M EVANS, J O'D MCGEE \\ From the University of Oxford, Nuffield Department of Pathology and Bacteriology, John Radcliffe Hospital, \\ Oxford
}

SUMMARY This study was undertaken to develop technology for the detection of nucleic acid using two different DNA probe reporter molecules, the ultimate aim being to differentially label two nucleic acids within the same nucleus. Digoxigenin and biotin were used to label DNA probes. The absolute and relative sensitivity of digoxigenin and biotin labelled DNA probes for detecting integrated human papilloma virus 16 (HPV16) was investigated in CaSki cells by non-isotopic in situ hybridisation (NISH). Several methods for the detection of labelled probes were also investigated. The optimal sensitivity of digoxigenin labelled probe was equivalent to that of biotin when alkaline phosphatase was used as the final detector. The median number of discrete viral signals discernible in each cell with the most sensitive detection system was seven to eight with both labelled probes. The average number of HPV16 genomes in each CaSki cell, derived by dot blot hybridisation, was about 270. The calculated absolute sensitivity of NISH for viral detection in this system is complex because of variation of signal size and number. Nevertheless, one signal per nucleus equates to as little as 30 to 40 viral copies, and probably much less.

The ability to distinguish up to 15 discrete signals with both digoxigenin and biotin labelled probes in the nuclei of CaSki cells indicates that these methods will be useful in interphase cytogenetics in material routinely fixed in aldehyde.

The detection of more than one nucleic acid sequence within the same cell in formalin fixed, paraffin wax embedded tissue has many applications in molecular and clinical pathology. Among these are the investigation of the infection of human tissues with virus(es) and interphase cytogenetics, whereby chromosome specific repeat probes analogous to $\mathrm{pHY} 2 \cdot 1^{1}$ are used to analyse the chromosome number of non-dividing cells. Another application of interphase cytogenetics is analysis of normal ${ }^{2}$ and malignant cell ${ }^{3}$ ontogeny in patients who have undergone sex-mismatched organ transplantation.

Biotinylated DNA probes have been used extensively in non-isotopic in situ hybridisation (NISH). ${ }^{46}$ Biotin labelled probes detect only a single sequence unless sequential hybridisation and detection procedures are used: these are technically time-consuming. Alternative reporter molecules, therefore,

Accepted for publication 2 February 1989 have been used in NISH for the detection of more than one DNA sequence. Aminoacetylfluorene and mercury labelled probes used simultaneously can differentially detect two nucleic acids in freshly isolated or cultured cells by fluorescence methods. ${ }^{7-10}$ Cohybridisation using these labels, however, results in nonspecific signals on metaphase chromosomes and in interphase nuclei. ${ }^{8}$ Fluorescence detection systems are not readily applicable to archival paraffin wax sections because of autofluorescence. Aminoacetylfluorene is also carcinogenic and mercury is toxic. For these reasons we explored other compounds for labelling DNA probes to enable colocalisation of nucleic acids in interphase nuclei in cells fixed in aldehyde. Of those explored, digoxigenin was the most useful.

Digoxigenin (fig 1), a derivative of the cardiac glycoside digoxin, conjugated to deoxyuridine triphosphate by an 11 carbon linker arm, can be used in the same way as biotin-dUTP to label DNA. Probes labelled with digoxigenin detect $0 \cdot 1 \mathrm{pg}$ of DNA by blot hybridisation (Boerhinger, West Germany). The sen- 

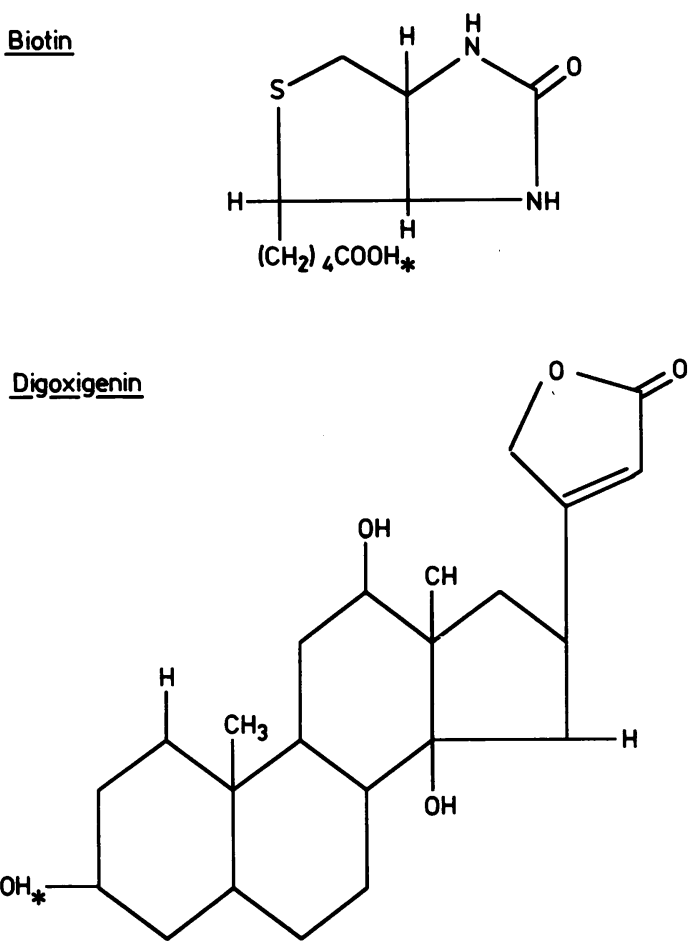

Fig 1 Structures of biotin and digoxigenin are shown. Both are incorporated into nucleic acids by conjugation to dUTP via an $11 \mathrm{C}$ linker arm at the sites indicated (*).

sitivity of digoxigenin in NISH is unknown. Biotinylated probes detect $32 \mathrm{fg}$ of DNA by blot hybridisation, ${ }^{11}$ unique sequences on Southern blots in 0.25 $\mu \mathrm{g}$ of genomic DNA, ${ }^{12}$ and single copy genes on chromosomes. ${ }^{4}$ The sensitivity of biotinylated probes used in NISH for detection of HPV in paraffin wax sections has been estimated by extrapolation from an internal non-viral control to be of the order of 10 viral copies. ${ }^{13}$

In this study the sensitivities of biotin and digoxigenin-labelled probes in NISH were analysed directly in a model system: CaSki cells were hybridised with an HPV16 probe into which these reporters were incorporated. Both probe types detected up to 15 discrete intranuclear signals. The most conservative estimate of sensitivity is that one signal (dot) per nucleus represents $30-40$ copies of virus and probably much less.

\section{Material and methods}

All chemicals were obtained from Sigma (UK) or BDH (UK), unless otherwise stated.

The HPV16 probe consisted of the whole viral genome cloned into pAT153.
LABELLING OF PROBES

1 Biotin was incorporated into plasmids by nick translation. Insert-containing plasmid $(1 \mu \mathrm{g})$ was nick translated in a final reaction volume of $50 \mu$ containing $0.02 \mathrm{mmol} / 1$ deoxyadenosine triphosphate (dATP), $0.02 \mathrm{mmol} / 1$ deoxycytidine triphosphate (dCTP), $0.02 \mathrm{mmol} / 1$ deoxyguanosine triphosphate (dGTP), 0.02 mmol/1 biotin-11-deoxyuridine triphosphate (dUTP) (BRL,UK), $50 \mathrm{mmol} / 1$ Tris-HCl, $\mathrm{pH}$ 7.5. $5 \mathrm{mmol} / 1 \mathrm{MgCl}_{2}, 250 \mathrm{ng}$ DNase 1 (BRL,UK), and 12 units DNA polymerase 1 (BRL,UK). The reaction mix was incubated for 150 minutes at $14^{\circ} \mathrm{C}$ and the reaction stopped by addition of ethylenediaminetetraacetic acid to a final concentration of $20 \mathrm{mmol} / \mathrm{l}$. Labelled probe was purified by ethanol precipitation after addition of a 100 -fold excess of sheared salmon sperm DNA as a carrier, and dissolved in $50 \mu \mathrm{l} 10$ $\mathrm{mmol} / 1 \mathrm{Tris}-\mathrm{HCl}, \mathrm{pH} 8.0$, containing $1 \mathrm{mmol} / 1$ edetic acid. Biotinylated probes were stored at $4^{\circ} \mathrm{C}$. This probe is referred to as bio-HPV16.

2 Digoxigenin-dUTP was introduced by nick translation under similar conditions. The reaction mix contained the same reagents but $0.013 \mathrm{mmol} / 1 \mathrm{dTTP}$, $0.007 \mathrm{mmol} / \mathrm{l}$ digoxigenin-dUTP (Boerhinger, West Germany) were substituted for the biotin-dUTP. Purification was achieved in the same way. This probe is termed dig-HPV16.

Incorporation of biotin and digoxigenin-dUTP was monitored by including ${ }^{3} \mathrm{H}$-dATP (Amersham, UK) in the reaction mix. On this basis incorporations of 12$15 \%$ for biotin and 4-5\% for digoxigenin were routinely achieved. The nick translated fragments with both labelled deoxynucleotides ranged from $50-1000$ base pairs with a median size of $200-400$ base pairs as determined by non-isotopic Southern blotting. ${ }^{11}$

\section{BLOT HYBRIDISATION}

DNA was extracted from $75 \times 10^{6}$ CaSki cells as described. ${ }^{12}$ HPV16 insert DNA was prepared by digestion with BamH1 and purified using dimethylaminoethyl (DEAE) paper (Schleicher \& Schuell, West Germany). Serial dilutions of insert and CaSki cell DNA were prepared as dots and hybridised with biotinylated HPV16 insert." The intensity of the reaction with CaSki cell DNA was compared with that obtained using only the insert and the copy number of HPV16 in CaSki cells calculated (fig 2).

\section{CaSki CElls}

These were grown to mid-log phase in RPMI 1640 medium (Gibco, UK) containing penicillin and streptomycin supplements (Gibco UK) in $80 \mathrm{~cm}^{2}$ flasks (Gibco, UK). After one treatment with trypsin and edetic acid (Gibco, UK) they were grown on four-spot multiwell slides (spot diameter $12 \mathrm{~mm}$ (Hendley, Essex)) in sterile Petri dishes. Fixation was performed in either methanol/acetic acid $(3: 1 ; v / v)$ for 15 minutes 




Fig 2 Decreasing serial dilutions from left to right of cellular DNA (a) and HPVI6 DNA insert purified from plasmid (b) hybridised with biotinylated HPV16 and detected, as previously described. ${ }^{.1}$ Cellular DNA (yield $1 \mathrm{mg}$ ) was extracted from $75 \times 10^{6}$ CaSki cells in mid-log phase.

at $22^{\circ} \mathrm{C}$, or $4 \%(\mathrm{w} / \mathrm{v})$ paraformaldehyde (Taab; UK) in phosphate buffered saline for 10 minutes at $22^{\circ} \mathrm{C}$. Slides were air dried and stored at room temperature.

\section{UNMASKING OF NUCLEIC ACIDS}

CaSki cells fixed in paraformaldehyde were incubated in proteinase $\mathbf{K}$ (Boehringer, West Germany) at a concentration of $0.1 \mu \mathrm{g} / \mathrm{ml}$ in PBS at $37^{\circ} \mathrm{C}$ for 15 minutes. Slides were washed thoroughly in distilled water followed by PBS and dried at $75^{\circ} \mathrm{C}$. No unmasking was performed on cells fixed in methanol/acetic acid.

\section{NISH}

1 Hybridisation: Aliquots of hybridisation mix $(9 \mu \mathrm{l})$ containing $10-20 \mathrm{ng}$ bio-HPV16 or dig-HPV16, together with $1 \mu \mathrm{g}$ sheared salmon sperm DNA (see above), were added to each well on multispot slides which were covered with a $14 \mathrm{~mm}$ glass coverslip (Chance, UK). The slides placed in a moist Terasaki plate. The hybridisation mix consisted of $50 \%$ formamide (Sigma, UK), 5\% dextran sulphate (BDH, UK), $2 \times \mathrm{SSC}$, and $0.05 \mathrm{~mol} / 1$ Tris- $\mathrm{HCl}, \mathrm{pH} \mathrm{7.3;} 1 \times$ $\mathrm{SSC}=0.15 \mathrm{~mol} / 1$ sodium chloride, $0.015 \mathrm{~mol} / 1$ sodium citrate. CaSki cells fixed in paraformaldehyde and probes were simultaneously denatured at $95^{\circ} \mathrm{C}$ for 15 minutes on a solid stainless steel plate in a hot air over and then hybridised at $42^{\circ} \mathrm{C}$ for two hours. Methanol/acetic acid fixed CaSki cells were denatured at $75^{\circ} \mathrm{C}$ for seven minutes and hybridised at $42^{\circ} \mathrm{C}$ for two hours.

2 Detection of hybridisation signal: Slides were washed in three changes of $4 \times \mathrm{SSC}$ at $22^{\circ} \mathrm{C}$ (five minutes each change), soaked in blocking agent TBT $(0.05 \mathrm{~mol} / 1$ Tris- $\mathrm{HCl}, 0 \cdot 10 \mathrm{~mol} / 1$ sodium chloride, $\mathrm{pH} 7 \cdot 2$, containing $3 \%$ bovine serum albumin (Sigma, UK) and $0.05 \%$ Triton $100(\mathrm{v} / \mathrm{v}))$ at $22^{\circ} \mathrm{C}$ for 10 minutes. Subsequent visualisation of signal was determined by the reporter molecule:

(i) For biotinylated probes two different enzyme conjugates were used: streptavidin-peroxidase (Dako,
UK) diluted $1 / 100$ in TBT, or streptavidin-alkaline phosphatase (Dako, UK) diluted $1 / 100$ in TBT. Sections were incubated at $22^{\circ} \mathrm{C}$ for 30 minutes in either conjugate. Unbound conjugate was removed by washing for five minutes twice in $0.05 \mathrm{mmol} / 1$ Tris$\mathrm{HCl}, 0.10 \mathrm{mmol} / 1 \mathrm{NaCl}$, pH 7.2 (TBS), and the sections incubated in peroxidase or alkaline phosphatase substrate.

The peroxidase substrate used was a combination of $\mathrm{H}_{2} \mathrm{O}_{2}$ and 3-amino-9-ethylcarbazole (AEC) (Sigma, UK): AEC ( $2 \mathrm{mg}$ ) was dissolved in $1.2 \mathrm{ml}$ dimethylsulphoxide (BDH, UK) in a glass tube and added to $10 \mathrm{ml}$ of $0.02 \mathrm{~mol} / \mathrm{l}$ acetate buffer, $\mathrm{pH} 5.0-5 \cdot 2$. Hydrogen peroxide $(0.8 \mu \mathrm{l}$ of $30 \%(\mathrm{v} / \mathrm{v}, \mathrm{BDH}, \mathrm{UK}))$ was added and the final mix used immediately. Slides were incubated in substrate at $22^{\circ} \mathrm{C}$ for 30 minutes and the reaction stopped by thorough washing in distilled water. This procedure is referred to as bio-1-P/C.

If amplification of the peroxidase-AEC signal was required slides were initially incubated in monoclonal mouse anti-biotin (Dako, UK) diluted 1/50 in TBT for 30 minutes. After washing in TBS, sections were sequentially incubated in biotinylated rabbit antimouse immunoglobulin $\left(22^{\circ} \mathrm{C}\right.$, for 30 minutes) then streptavidin-peroxidase $\left(22^{\circ} \mathrm{C}\right.$ for 30 minutes $)$. Both the latter components were from Zymed, USA. ${ }^{14}$ The signal was developed using AEC as described below. This procedure is referred to as bio-3-P/C.

The alkaline phosphatase substrate consisted of nitroblue tetrazolium (NBT) and 5-bromo-4-chloro-3indolyl-phosphate (BCIP). This was made up as previously described, ${ }^{7}$ and stored in aliquots at $-20^{\circ} \mathrm{C}$ until required. Slides were incubated in this substrate at $22^{\circ} \mathrm{C}$ for 30 minutes and the reaction stopped by washing in distilled water. This procedure is referred to as bio-1-A/N.

(ii) For digoxigenin labelled probes slides were incubated for 30 minutes in alkaline-phosphatase conjugated anti-digoxigenin diluted $1 / 600$ in TBT (Boerhinger, West Germany), then washed in TBS. This single step procedure is referred to as $\operatorname{dig}-1-A / N$. 


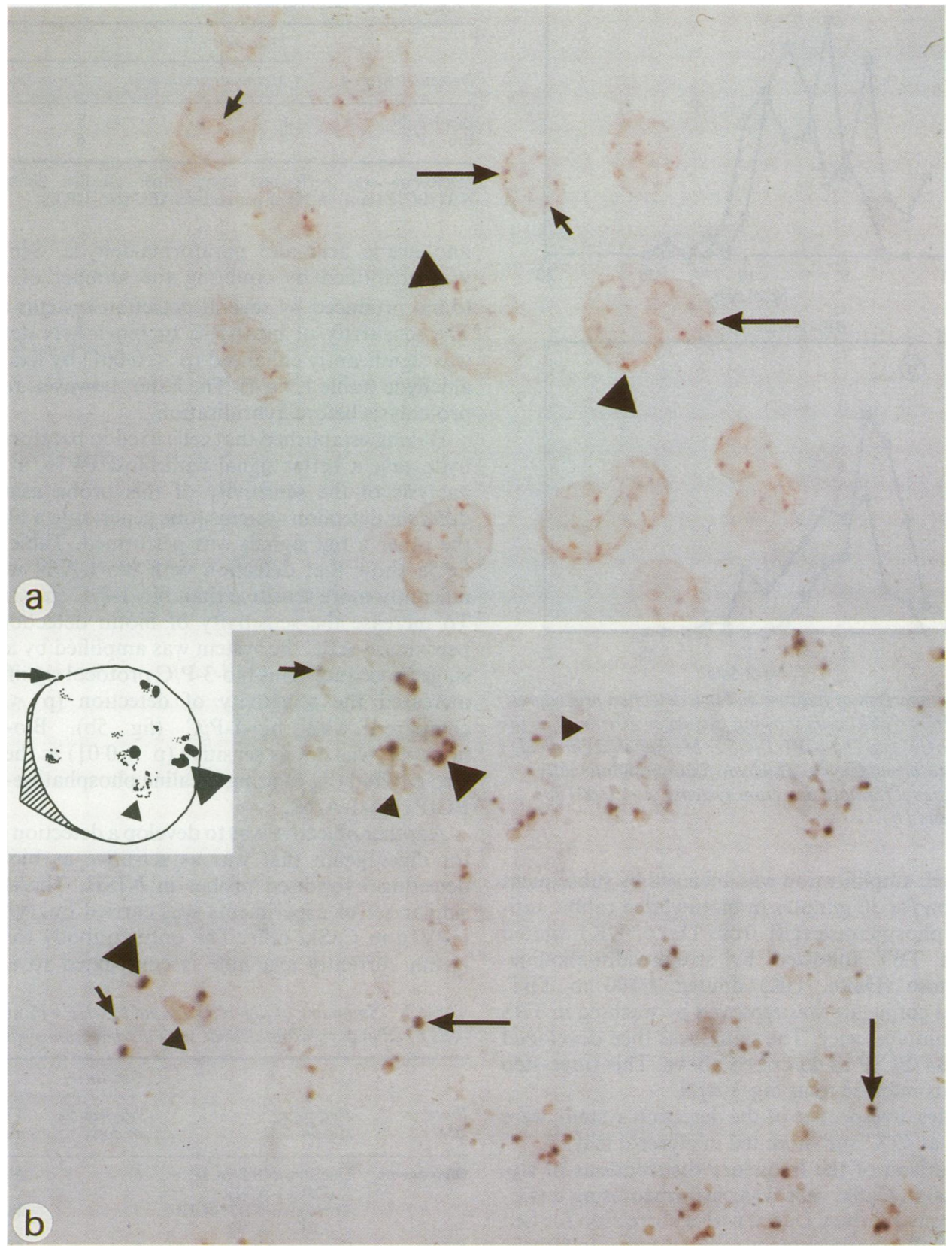

Fig 3 CaSki cells fixed in paraformaldehyde probed with HPV16. In (a) bio-HPV16 has been detected using streptavidin-peroxidase-AEC (bio-1-P/C) and in $(b)$ dig-HPV16 has been detected using antidigoxigenin alkaline phosphatase-NBT/BCIP (dig-1-A/N). Note that dot size varies from very small (small arrows) to large (large arrows), or confluent dots (large arrowheads). Unstained nucleoli are indicated (small arrowheads). Boxed insert shows detail of adjacent cell nucleus: note nuclear membrane. 
596
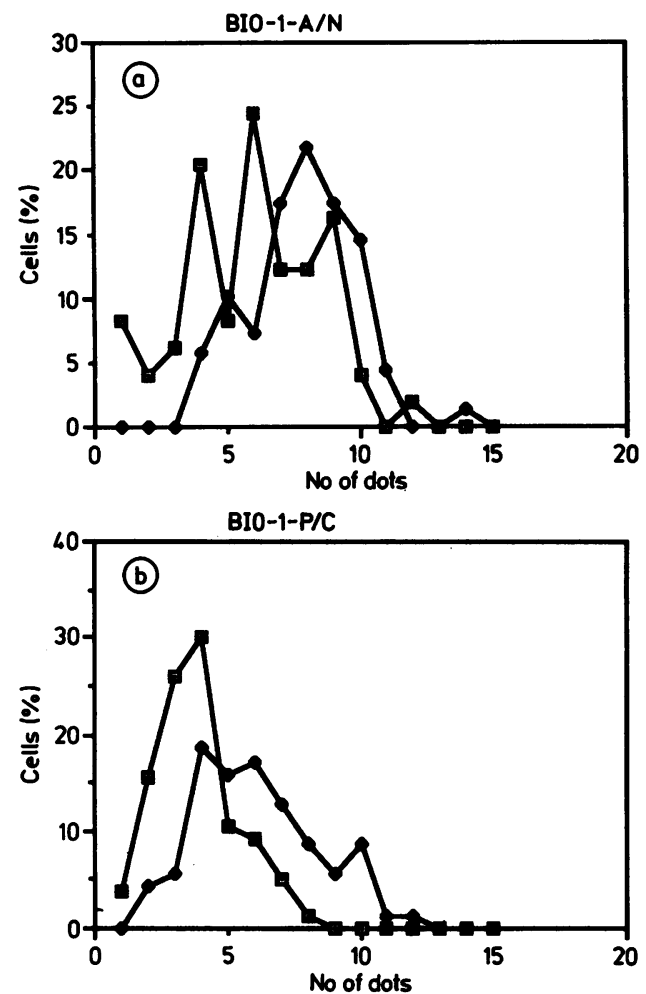

Fig 4 Comparison of fixation and two detection procedures for HPVI6 in CaSki cells showing frequency distributions for (a) bio-1-A/N and (b) bio-1-P/C. $\square$ Methanol/acetic acid, 4\% paraformaldehyde. Aldehyde fixation significantly enhances signal for both detection systems: $p<0.001$ for both $(a)$ and $(b)$.

If required, amplification was achieved by subsequent incubation for $\mathbf{3 0}$ minutes in biotinylated rabbit antialkaline phosphatase (gift from Dako, UK) diluted $1 / 500$ in TBT followed by streptavidin-alkalinephosphatase (Dako, UK) diluted 1/100 in TBT. Unbound conjugate was removed by washing in TBS for five minutes twice. The signal was then developed using NBT/BCIP as described above. This three-step protocol is referred to as dig-3-A/N.

All slides, irrespective of the detection system, were air-dried at $42^{\circ} \mathrm{C}$ and mounted in glycerol jelly.

Comparison of the frequency distributions of signals (dots) in CaSki cells was performed using a twotailed Mann-Whitney $U$ test, with a correction for tied values. In all experiments the signal number in 80 cells was counted.

\section{Results}

The relative sensitivity of biotin and digoxigenin labelled probes in detecting integrated HPV16 by NISH was investigated in CaSki cells fixed in meth-
Herrington, Burns, Graham, Evans, McGee

Table 1 Median number of dots per CaSki cell hybridised with bio-HPV16 and fixed with either methanol/acetic acid $(3: 1 ; v / v)$ or $4 \%$ paraformaldehyde*

\begin{tabular}{lll}
\hline & \multicolumn{2}{l}{ Fixative } \\
\cline { 2 - 3 } Detection method & Methanol/acetic acid & Paraformaldehyde \\
\hline Bio-1-A/N & 6 & 8 \\
Bio-1-P/C & 4 & 6
\end{tabular}

*Detection was performed using either alkaline phosphataseNBT/BCIP (bio-1-A/N) or peroxidase-AEC (bio-1-P/C).

anol/acetic acid and paraformaldehyde. Sensitivity was quantified by counting the number of signals (dots) produced by several detection systems (fig 3). The sensitivity of bio-1-P/C or bio-1-A/N detection was significantly enhanced $(p<0.001)$ by fixation in aldehyde (table 1, fig 4). The latter, however, requires proteolysis before hybridisation.

Having established that cells fixed in paraformaldehyde gave a better signal with bio-HPV16, a formal analysis of the sensitivity of this probe using two different detection systems (one generating a blue and the other a red signal) was performed. Table 2 and fig 5a show that detection with bio-1-A/N was significantly more sensitive than bio-1-P/C ( $p<0.001)$. To increase the sensitivity of biotin detection with peroxidase-AEC the system was amplified by a threestage procedure. This bio-3-P/C protocol significantly increased the sensitivity of detection $(p<0.05)$ compared with bio-1-P/C (fig $5 b$ ). Bio-3-P/C, however, was not as sensitive $(\mathrm{p}<0.01)$ as the single step method (fig 6) using alkaline phosphatase- NBT/ BCIP (bio-1-A/N).

Another objective was to develop a detection system for digoxigenin that was as sensitive as biotin for detecting hybridised probes in NISH. Therefore, a similar set of experiments was carried out with digHPV16 in CaSki cells. The only antibody to digoxigenin currently available is conjugated to alkaline

Table 2 Summary of dig-HPV16 and bio-HPV16 in CaSki cells fixed in paraformaldehyde with all detection systems*.

\begin{tabular}{llll}
\hline & & \multicolumn{2}{l}{ Sensitivity } \\
\cline { 3 - 4 } $\begin{array}{l}\text { Probe } \\
\text { label }\end{array}$ & $\begin{array}{l}\text { Detection } \\
\text { system }\end{array}$ & $\begin{array}{l}\text { Median No } \\
\text { of dots }\end{array}$ & $\begin{array}{l}\text { Viral copy } \\
\text { number }\end{array}$ \\
\hline Digoxigenin: & $\begin{array}{l}\text { One step-NBT/BCIP } \\
\text { (DIG-1-A/N) } \\
\text { Three step-NBT/BCIP } \\
\text { BIG-3-A/N) }\end{array}$ & 6 & 45 \\
$\begin{array}{c}\text { One step-AEC } \\
\text { (BIO-1-P/C) }\end{array}$ & 6 & 38 \\
$\begin{array}{c}\text { Three step-AEC } \\
\text { (BIO-3-P/C) } \\
\text { One step-NBT/BCIP } \\
\text { (BIO-1-A/N) }\end{array}$ & 8 & 45 \\
\end{tabular}

* Sensitivity is shown as median dot number per CaSki cell. The approximate equivalent viral copy number per dot is calculated from the mean of the two experiments shown in fig 2 . 

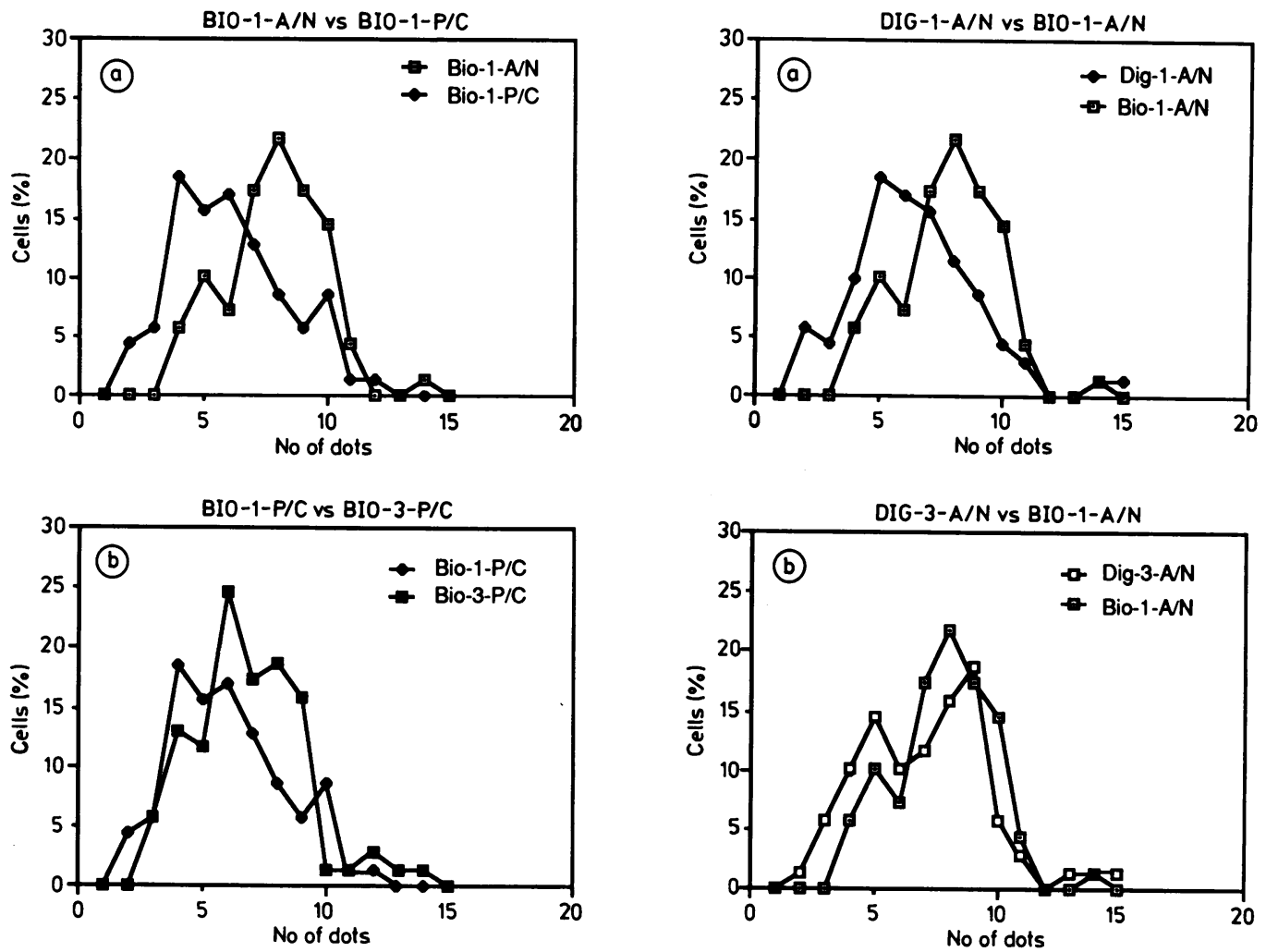

Fig 5 Comparison of different detection systems for bio$H P V 16$ in CaSki cells fixed in paraformaldehyde: $(a) \square$ $B i o-1-A / N$ is more sensitive than $\rightarrow B i o-1-P / C(p<0.001)$; (b) the sensitivity of bio-1-P/C detection can be enhanced using the three step procedure $(\square$ bio-3-P/C)-p $<0.05$.

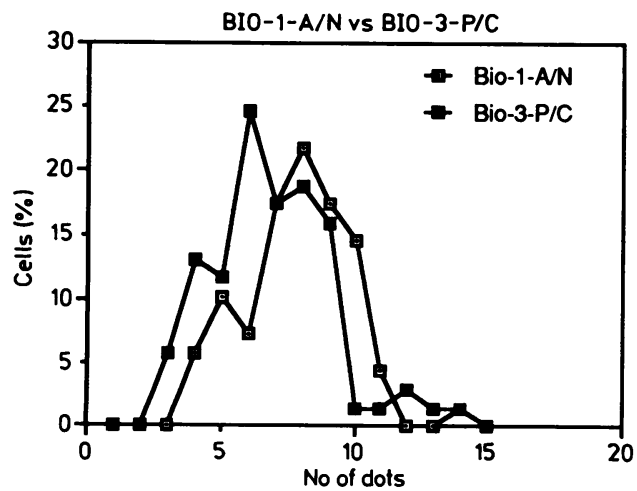

Fig 6 Comparison of bio-HPV16 detection with alkaline phosphatase and peroxidase substrates. Despite amplification using the three step method, the peroxidase-carbazole detection system ( $\mathrm{bio}-3-P / C)$ is not as sensitive $(p<$ 0.01 ) as bio-1-A/N (曰).

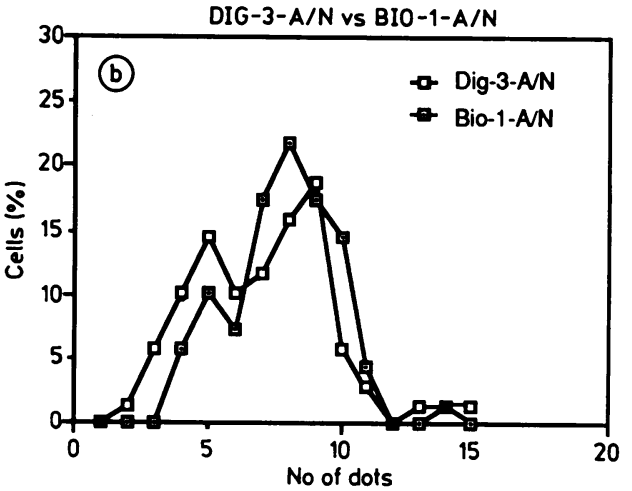

Fig 7 Comparison of dig-HPV16 and bio-HPV16 detection using three detection systems. (a) The sensitivity of digoxigenin in a one-step detection system $(\diamond$ dig-1-A/N) is less $(p<0.001)$ than the corresponding system using biotin ( $\square$ bio-1-A/N). (b) Amplification of the digoxigenin signal $(\square$ dig-3-A/N) increases its sensitivity $(0.1>p>0.05)$ to that of biotin ( $\square$ bio-1-A/N).

phosphatase and hence detection entailed the use of NBT/BCIP. One step detection (dig-1-A/N) was less sensitive $(p<0.001)$ (fig 7a) than the comparable detection system for bio-HPV16 - that is, bio-1-A/N. Amplification using the three stage procedure (dig-3$A / N$ ) increased the sensitivity to that of bio-1-A/N ( $p$ $>0.05$ ) (fig 7b).

The final goal of this series of experiments was to establish systems for the detection of both digoxigenin and biotin labelled probes with equal sensitivity using substrate products of contrasting colours. The detection of bio-HPV16 using the red substrate AEC was therefore compared with the detection of dig-HPV16 with the blue substrate NBT/BCIP. Bio-1-P/C was of equivalent sensitivity $(p=0.4)$ to dig-1-A/N (fig 8A). When both systems were amplified - that is, bio-3-P/C and dig-3-A/N-comparable sensitivity $(\mathrm{p}=0.45)$ was maintained (fig 8b).

The average number of copies of HPV16 in CaSki 

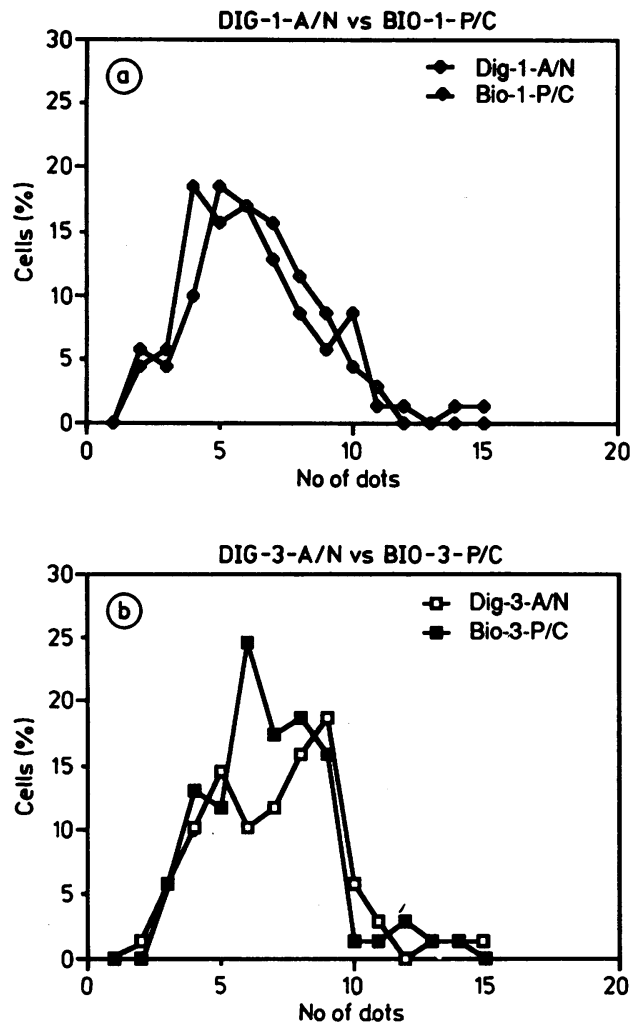

Fig 8 Comparison of HPVI6 detection using single and three step detection systems. (a) Detection of bio-HPV16 using the peroxidase- $A E C$ system, bio-1-P/C $(\diamond)$ is as sensitive $(p=0.4)$ as the detection of dig-HPVI6 using alkaline phosphatase NBT/BCIP (dig-1-A/N $\bullet$ ). (b) Amplification using the three-stage procedure gave equal sensitivity $(p=0.45)$ for dig-3-A/N ( $\square)$ and bio-3-P/C (ם).

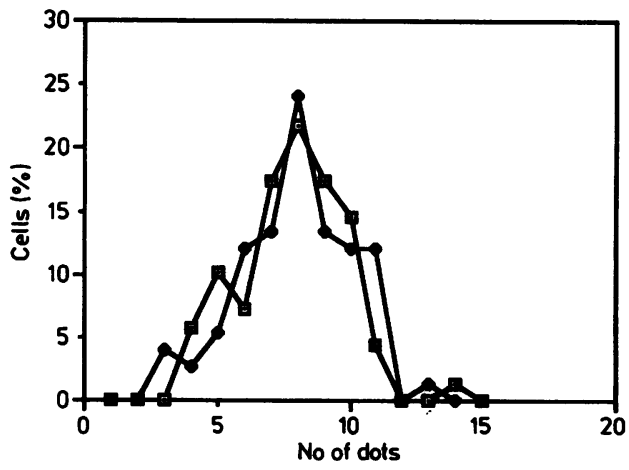

Fig 9 Reproducibility of dot number per cell in two separate experiments using bio-HPV16 as probe and the single step alkaline phosphatase detection system (bio-1-A/N). The distributions of dots show no difference $(p=0.52)$. Experiment $1=\bullet$; experiment $2=\square$. cells at mid-log phase was calculated from fig 2 as follows. The dots indicated by arrows for human DNA - that is, $2 \mathrm{ng}$ - and HPV16 insert (425 fg) are of equivalent intensity. As a diploid genome contains 6.6 $\times 10^{9}$ base pairs and the molecular size of HPV16 is 7904 base pairs, the number of copies of HPV16 per CaSki cell is 175; it is known, however, that CaSki cells are hyperdiploid. ${ }^{17}$ On the assumption that the average molecular weight of one base pair is 650 daltons, $1 \mathrm{mg}$ of cellular DNA is equivalent to $1.2 \times 10^{9}$ base pairs. The copy number per cell is therefore 320 . Repetition of this experiment yielded a number of 220 ; therefore, the copy number used in all calculations was 270 . The experimentally derived number of base pairs per cell agrees with that derived from the modal chromosome number in CaSki cells-82. ${ }^{17}$ Given the assumption, which is unlikely to be valid, that each cell contains the same number of viral genomes of the same sizeeight kilobase pairs, one dot equates to 30 to 40 viral genomes using the most sensitive NISH detection system reported here for both biotin and digoxigenin labelled DNA probes. The relative sensitivity of each detection system is summarised in table 2.

The reproducibility of detecting HPV16 with bio-1$\mathrm{A} / \mathrm{N}$, the most sensitive system, was assessed by analysing the signal frequency distributions in separate experiments. This showed no significant difference $(p=0.52)$ between the two sets of data (fig 9).

\section{Discussion}

This study shows that digoxigenin labelled probes are as simple to produce and use as biotin labelled probes and are of virtually equivalent sensitivity in the detection of nucleic acid. Digoxigenin does not have the disadvantage of background due to endogenous biotin, which can be a problem in tissues such as liver. The theoretical disadvantage of steric hindrance and hence poor incorporation in nick translation reactions and inefficient hybridisation is not a problem if the conditions are controlled to restrict digoxigenin incorporation to every 20 th to 25 th nucleotide. The only difference this makes in methodological terms, compared with biotin, is that the sections are exposed to substrate for slightly longer as there is less enzyme bound to the labelled nucleic acid. For NISH, however, increasing the incorporation of digoxigenin by reducing the amount of TTP may enhance the sensitivity of digoxigenin labelled probes: this is being investigated. In this laboratory, however, there is no direct correlation between the degree of substitution of biotin-dUTP in probes and their effectiveness in NISH. The single most important factor seems to be size of probe (Evans and $\mathrm{McGee}$, unpublished observations).

CaSki cells fixed in paraformaldehyde, after 
proteolysis, gave a better signal than cells fixed in methanol/acetic acid. The following discussion, therefore, refers only to cells fixed in aldehyde.

The peroxidase-AEC detection system (bio-1-P/C) is less sensitive than alkaline phosphatase-NBT/BCIP (bio-1-A/N) but is equivalent to the single step detection procedure using digoxigenin as reporter molecule (dig-1-A/N). Amplification of the signal produced by digoxigenin (dig-3-A/N) increases the sensitivity to that of bio-1-A/N. As this requires an avidin conjugate, however, part of the theoretical advantage is negated if simultaneous hybridisation and detection with biotin and digoxigenin probes is required. ${ }^{15}$ Although the amplified detection systems bio-3-P/C and dig-3-A/N are slightly more sensitive, they are technically more time consuming because the reagents currently available require each probe label to be detected sequentially. In routine clinical practice, therefore, the differences in sensitivity between dig-1$\mathrm{A} / \mathrm{N}$ and bio-1-P/C by comparison with the three step procedures are not significant. These two detection systems can be used for simultaneous differential detection of two nucleic acids within the same nucleus in formalin fixed, paraffin wax embedded material. ${ }^{15}$

The sensitivity of bio and dig-HPV16 for the detection of integrated HPV16 was analysed using the CaSki cell line, which has been estimated previously to contain greater than 500 viral copies per cell, although the phase of cell growth was not stipulated. ${ }^{16}$ In this laboratory CaSki cells contain about 270 copies of HPV16 in mid-log phase (fig 2). An estimate of the sensitivity of various detection systems was made by counting the number of discrete signals per cell and using the median as a measure of central tendency of the resulting frequency distribution (table 2). Because seven to eight dots were seen in each cell with the most sensitive systems, the simple conclusion is that each dot represents about 30 to 40 copies of HPV16. This is likely to be an underestimate of absolute NISH sensitivity (see below): the HPV16 genome is integrated into the host genome of CaSki cells in at least 11 different chromosome sites. ${ }^{17}$ These integrated segments comprise either the whole HPV16 genome (7.9 kilobase pairs, or segments with either a deletion (6.5 kilobase pairs), or reduplication (10.5 kilobase pairs). ${ }^{18}$ The calculation of quantitative sensitivity by division of the experimentally derived copy number by the median number of dots assumes that the copies are evenly distributed throughout the CaSki cell genome. The copies, however, are arranged as tandem repeats clustered at the sites of integration. The relation between these clusters is affected by spatial constraints in interphase nuclei and the resolution and hence sensitivity of any detection system using ordinary light microscopic optics, may be limited by the superimposition of signals both within and between clusters. Therefore, in the absence of background staining, the maximum number of dots is likely to equal the number of integration sites if it is assumed (see below) that resolution is insufficient to distinguish several copies within a cluster. Because there are at least 11 integrations sites and the viral copy number per cell is 270 , one would expect 11 dots per cell if the sensitivity of NISH signal were greater than or equal to 24 copies, if it is assumed that these copies are equally distributed among these sites. If the sensitivity were less than this, the dot number should be 0 . The median number of dots was seven to eight, which approaches the theoretical maximum, but it is likely that the HPV copy number per cell varies, as the chromosome number varies between cells (75-84; mode 82 ), and integration occurs into both normal and abnormal chromosomes. ${ }^{17}$ Furthermore, the copies are likely to be distributed unevenly between the integration sites and, being repetitive, are possible sites of frequent recombination. These considerations would explain the variability in the number of dots per cell despite the clonal origin of CaSki cells.

Adjacent intense large NISH signals tend to coalesce and become double, triple etc dots which become indistinguishable (figs $3 a$ and $b$ ). The latter large dots, therefore, possibly represent multiple HPV 16 copies at a single or adjacent chromosomal site(s) and the variation in size may be due to either superimposition of signals from adjacent clusters or the variation in copy number per integration site. Thus the assumption inherent in our calculation that each NISH dot, irrespective of its size, represents the same number of viral copies is unlikely to be true. This is supported by the fact that the single signal obtained using pHY2.1 represents 2000 copies of a repeat sequence on the $\mathrm{Y}$ chromosome.'

All of these factors will produce an underestimate of NISH sensitivity in this model system when compared with dot hybridisation. This, and the above considerations, indicate that each NISH signal in CaSki cells represents less than to 30 to $\mathbf{4 0}$ copies of virus. This compares with estimates of NISH sensitivity of 30 copies of HPV16 per cell on frozen sections, ${ }^{19} 10$ to 50 copies of HPV18 per HeLa cell in culture, ${ }^{20}$ and 10 copies per cell in formalin fixed, paraffin wax embedded biopsy specimens. ${ }^{13}$

The fact that the viral DNA is integrated implies that these cells form an appropriate model for the study of the mammalian interphase cell nucleus. The ability to distinguish at least 15 discrete dots in a single nucleus has implications for the application of this system to interphase cytogenetics. By labelling chromosome specific repeat probes, up to seven pairs of chromosomes could theoretically be detectable in the same nucleus if probe cocktails were used. The detection of one chromosome using each label would 
permit identification of two chromosome pairs (and also any aberrations) per nucleus in solid human tumours. The entire chromosome complement of cells could therefore be analysed on three four-spot multiwell slides. These theoretical possibities are now being investigated.

CSH is a Cancer Research Campaign Clinical Research Fellow and a Junior Research Fellow of Green College (University of Oxford). The work was supported by grants to JO'D McG from the Cancer Research Campaign (UK).

\section{References}

1 Burns J, Chan VT-W, Jonasson JA, Fleming KA, Taylor S, McGee JO'D. Sensitive system for visualising biotinylated DNA probes hybridised in situ: rapid sex determination of intact cells. J Clin Pathol 1985;38:1085-92.

2 Reittie JE, Poulter JW, Prentice HG, et al. Differential recovery of phenotypically and functionally distinct circulating antigenpresenting cells after allogeneic marrow transplantation. Transplantation 1988;45:1084-91.

3 Lyttleton MPA, Browett PJ, Brenner MK, et al. Prolonged remission of Epstein-Barr virus associated lymphoma secondary to $\mathrm{T}$ cell depleted bone marrow transplantation. Bone Marrow Transplantation 1988;3:641-6.

4 Bhatt B, Burns J, Flannery D, McGee JO'D. Direct visualisation of single copy genes on banded metaphase chromosomes by nonisotopic in situ hybridisation. Nucleic Acids Res 1988;16:3951-61.

5 Burns J, Graham AK, McGee JO'D. Non-isotopic detection of in situ nuclei acid in cervix: an updated protocol. J Clin Pathol 1988;41:897-9.

6 Matthews JA, Kricka LJ. Analytical strategies for the use of DNA probes. Analyt Biochem 1988;169:1-25.

7 Hopman AHN, Ramaekers FCS, Raap AK, et al. In situ hybridisation as a tool to study numerical chromosome aberrations in solid bladder tumours. Histochemistry 1988;89:307-16.

8 Cremer T, Tesin D, Hopman AHN, Manuelidis L. Rapid interphase and metaphase assessment of specific chromosomal changes in neuroectodermal tumour cells by in situ hybridisation with chemically modified DNA probes. Exp Cell Res 1988;176:199-220.
9 Trask B, Van Den Engh G, Pinkel D, et al. Fluorescence in situ hybridisation to interphase cell nuclei in suspension allows flow cytometric analysis of chromosome content and microscopic analysis of nuclear organisation. Hum Genet 1988;78:251-9.

10 Devilee P, Thierry RF, Kievits T, et al. Detection of chromosome aneuploidy in interphase nuclei from human primary breast tumours using chromosome-specific repetitive DNA probes. Cancer Res 1988;48:5825-30.

11 Chan VT-W, Fleming KA, McGee JO'D. Detection of subpicogram quantities of specific DNA sequences on blot hybridisation with biotinylated probes. Nucleic Acid Res 1985;13:8083-91.

12 Chan VT-W, Fleming KA, McGee JO'D. Simultaneous extraction from clinical biopsies of high-molecular-weight DNA and RNA: comparative characterisation by biotinylated and ${ }^{32} \mathrm{P}$ labelled probes on Southern and Northern blots. Analyt Biochem 1988;168:16-24.

13 Burns J, Graham AK, Frank C, Fleming KA, Evans MF, McGee JO'D. Detection of low copy human papilloma virus DNA and mRNA in routine paraffin sections of cervix by non-isotopic in situ hybridisation. J Clin Pathol 1987;40:858-64.

14 Allan GM, Todd D, Smyth JA, Mackie DP, Burns J, McNulty MS. In situ hybridisation: an optimised protocol for a biotinylated DNA probe renders it more sensitive than a comparable ${ }^{35} S$ labelled probe. $J$ Virol Methods (In press).

15 Herrington CS, Burns J, Graham AK, Bhatt B, McGee JO'D. Interphase cytogenetics using biotin and digoxigenin labelled probes II: simultaneous detection of two nucleic acid species in individual nuclei. J Clin Pathol 1989;41:601-6.

16 Yee C, Krishnan-Hewlett I, Baker CC, Schlegel R, Howley PM. Presence and expression of human papillomavirus sequences in human cervical carcinoma cell lines. Am J Pathol 1985;119: $361-6$.

17 Mincheva A, Gissman L, Zur Hausen H. Chromosomal integration sites of human papillomavirus DNA in three cervical cancer cell lines mapped by in situ hybridisation. Med Microbiol Immun 1987;176:245-56.

18 Baker CC, Phelps WC, Lindgren V, Braun MJ, Gonda MJ, Howley PM. Structural and transcriptional analysis of human papillomavirus type 16 sequences in cervical carcinoma cell lines. J Virol 1987;61:962-71.

19 Walboomers JMM, Melchers WJG, Mullink H, et al. Sensitivity of in situ detection with biotinylated probes of human papilloma virus type 16 DNA in frozen tissue sections of squamous cell carcinomas of the cervix. Am J Pathol 1988;131:587-94.

20 Syrjanen S, Partanen P, Mantyjarvi R, Syrjanen K. Sensitivity of in situ hybridisation techniques using biotin- and ${ }^{35} \mathrm{~S}$-labelled human papillomavirus (HPV) DNA probes. J Virol Methods 1988;19:225-38. 